\title{
C\&D waste for road construction: long time performance of roads constructed using recycled aggregate for unbound pavement layers
}

\author{
F. Lancieri, A. Marradi \& S. Mannucci \\ Civil Engineering Department - Road and Transportation Division, \\ University of Pisa, Italy
}

\begin{abstract}
This paper describes the results of the experimental measurements carried out during 2001 and 2005 on two secondary roads built in 1998 using C\&D aggregates for subgrade and subbase layers. Field data included structural data in the form of nondestructive testing (NDT) performed with a Falling Weight Deflectometer and laser profilometer, visual condition survey, traffic measurements and construction and maintenance history data. The FWD deflection measurements were analysed to determine modulus values for the various pavement layers while profile data were used to calculate evenness index (IRI). Deflection tests performed in 2001 showed that in-situ pavement performance was better than expected. This performance improvement was explained by self-cementing properties. Field tests repeated in 2005 revealed a meaningful difference in the structural behavior of the road pavements examined: the first, subjected to heavy vehicles, showed a marked improvement in backcalculated moduli of the subbase pavement layer while the second, not subjected to heavy vehicles, maintained practically the same values of layer moduli. These field tests were integrated with laboratory tests performed in order to investigate the time evolution of mechanical characteristics of C\&D materials and to evaluate the influence of compaction techniques on the improvement in resistance recorded with the gyratory compactor. The data and results presented confirm that road construction could offer a reliable use for C\&D waste recycling.
\end{abstract}

Keywords: $C \& D$, unbound layers, $F W D$, back analysis, gyratory compactor. 


\section{Introduction}

During the last ten years, road works in Italy have on various occasions been carried out using recycled aggregate from construction and demolition waste, although codes for materials specifications have included such materials only since 2002.

The legislation currently in force in Italy requires Italian public authorities working in the field of building, road and environmental construction to cover at least $30 \%$ of their annual requirement of aggregate by using recycled aggregate. In the light of the provisions laid down in current legislation and the increasing difficulty in obtaining virgin materials, it is important to ascertain the type of mechanical performance that can truly be achieved by C\&D materials once they have been set in place, and how their characteristics evolve over time as a function of their physical, mechanical and compositional acceptability requisites.

In order to improve and extend knowledge on these aspects, investigations were conducted at the Road Research Laboratory Civil Engineering Department of the University of Pisa, in order to assess the aggregate utilized in the construction of two road section in 1998. During subgrade and subbase construction, field tests were conducted to check that materials were correctly set in place (load plate test, dry density measurements). Subsequently, in 2001 and 2005, non-destructive Dynatest Falling Weight Deflectometer (FWD) testing was performed to monitor the evolution over time of the mechanical parameters of the pavement layers built with C\&D materials. In 2005 the road profile of the two sites investigated was also assessed, by calculating the IRI (International Roughness Index) in order to evaluate surface evenness. For both infrastructures, whose pavement was not subjected to maintenance operations, two $200 \mathrm{~m}$ long sample sections were examined in the present study.

\section{Description of the experimental roads}

The sections subjected to investigation form part of two secondary roads, situated on the outskirts of the city of Pisa, opened to traffic in 1998. For both pavements the subbase layer was built with unbound recycled aggregate (a scheme of the pavement is shown in Figure 1). The two infrastructures are characterized by a different road section: the road indicated henceforth as Road 1 is constituted by a single carriageway with one lane in each direction, while the one indicated as Road 2 is constituted by a carriageway with two lanes in each direction.

In the 2001 and 2005 tests, vehicular traffic was also measured using magnetic induction sensors placed on the road pavement. The two roads were found to be subjected to appreciably different amounts and types of traffic: Road 1, during its eight years of use, had a constant TGM value of roughly $5000 \mathrm{v} / \mathrm{d}$, with $6 \%$ of heavy vehicles, while Road 2 had a very modest TGM composed of passenger automobiles. 
Road I

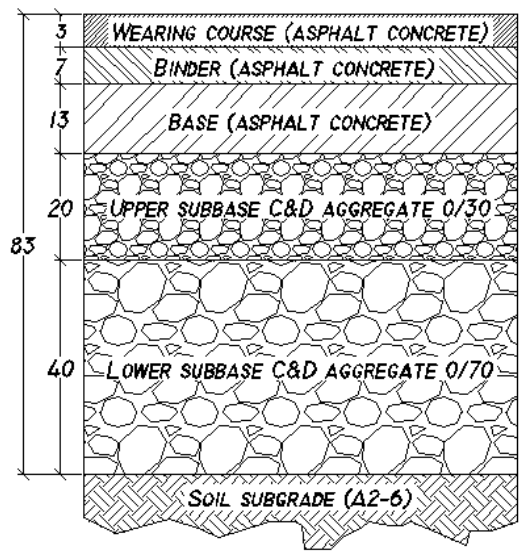

$\operatorname{Road} 2$

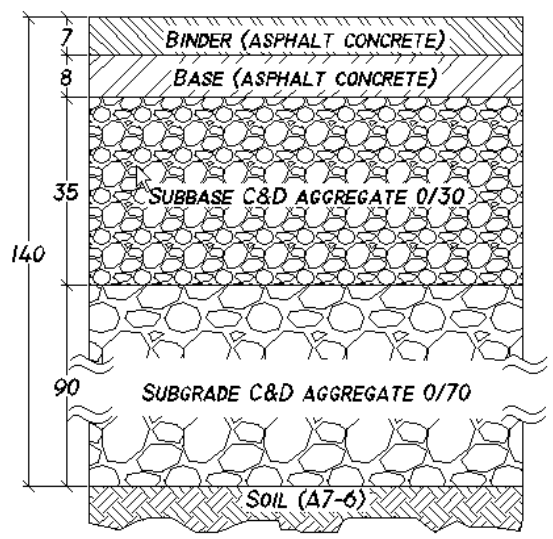

Figure 1: $\quad$ Scheme of pavements (measures in $\mathrm{cm}$ ).

\section{Tests at the end of construction works: year 1998}

The characteristics of materials utilized for the asphalt concrete are shown in Table 1.

Table 1: Properties of asphalt concrete.

\begin{tabular}{|l|c|c|c|c|c|}
\hline Experimental site & \multicolumn{3}{|c|}{ Road 1 } & \multicolumn{2}{c|}{ Road 2 } \\
\hline Layer & wearing & binder & base & binder & base \\
\hline Binder content (\%) & 5.6 & 4.8 & 4.5 & 4.9 & 4.3 \\
\hline Voids content (\%) & 5.5 & 8.3 & 10.0 & 9.1 & 10.6 \\
\hline Marshall stability (kN) & 9.43 & 8.32 & 7.38 & 7.61 & 6.84 \\
\hline
\end{tabular}

With regard to the $C \& D$ materials, in order to gain insight into the evolution of the mechanical characteristics over time, with reference for example to selfcementing properties, it is important also to have information on the composition of the mixtures utilized (Table 2).

Table 2: $\quad C \& D$ aggregate composition (material retained $4 \mathrm{~mm}$ sieve).

\begin{tabular}{|c|c|c|c|c|c|c|c|}
\hline \multicolumn{2}{|c|}{$\begin{array}{c}\text { Components } \\
\text { (Weight \%) }\end{array}$} & $\begin{array}{c}\text { Concrete } \\
\text { and Gravel }\end{array}$ & $\begin{array}{c}\text { Brick and } \\
\text { ceramic }\end{array}$ & Mortar & Glass & Asphalt & $\begin{array}{l}\text { Clay } \\
\text { lumps }\end{array}$ \\
\hline \multirow{2}{*}{$\begin{array}{l}\bar{Z} \\
\stackrel{\tilde{Z}}{\simeq}\end{array}$} & C\&D 0/30 & 55.5 & 24.8 & 17.5 & 0.2 & 2.0 & 0.0 \\
\hline & C\&D 0/70 & 54.7 & 25.6 & 4.7 & 0.4 & 14.6 & 0.0 \\
\hline \multirow{2}{*}{$\begin{array}{l}\text { N } \\
\stackrel{\tilde{O}}{\mathscr{2}} \\
\end{array}$} & C\&D 0/30 & 56.1 & 29.0 & 10.8 & 0.4 & 3.7 & 0.0 \\
\hline & C\&D 0/70 & 52.0 & 23.4 & 3.2 & 0.4 & 12.3 & 8.7 \\
\hline
\end{tabular}


The results of the characterization tests undertaken on the different types of C\&D materials utilized in contructing the two roads are shown in Table 3, Marradi [1].

Table 3: Properties of recycled aggregates.

\begin{tabular}{|l|c|c|c|c|}
\hline \multicolumn{1}{|c|}{ Experimental site } & \multicolumn{2}{c|}{ Road 1 } & \multicolumn{2}{c|}{ Road 2 } \\
\hline \multicolumn{1}{|c|}{ Material } & $\begin{array}{c}\text { C\&D } \\
0 / 30\end{array}$ & $\begin{array}{c}\text { C\&D } \\
0 / 70\end{array}$ & $\begin{array}{c}\text { C\&D } \\
0 / 30\end{array}$ & $\begin{array}{c}\text { C\&D } \\
0 / 70\end{array}$ \\
\hline \% Passing 2.5" ASTM sieve $(63,5 \mathrm{~mm})$ & 100 & 100 & 100 & 100 \\
\hline \% Passing 1.0" ASTM sieve $(25,4 \mathrm{~mm})$ & 100 & 80 & 95 & 90 \\
\hline \% Passing 10 ASTM sieve $(2,00 \mathrm{~mm})$ & 39 & 22 & 46 & 62 \\
\hline \% Passing 40 ASTM sieve $(0,42 \mathrm{~mm})$ & 26 & 15 & 32 & 41 \\
\hline \% Passing 200 ASTM sieve $(0,075 \mathrm{~mm})$ & 13 & 8 & 11 & 19 \\
\hline Liquid limit $\mathrm{w}_{\mathrm{L}}(\%)$ & n.p. & n.p. & n.p. & 30 \\
\hline Plastic limit $\mathrm{w}_{\mathrm{P}}(\%)$ & n.p. & n.p. & n.p. & 21 \\
\hline Plasticity index PI (\%) & n.p. & n.p. & n.p. & 9 \\
\hline Los Angeles abrasion coefficient LA (\%) $)^{(1)}$ & 41 & 43 & 39 & 42 \\
\hline AASHTO Maximum dry density $\gamma_{\mathrm{dmax}}\left(\mathrm{Mg} / \mathrm{m}^{3}\right)$ & 1.88 & 1.95 & 1.92 & 1.86 \\
\hline AASHTO optimum moisture content $\mathrm{w}_{\text {opt }}(\%)$ & 11.0 & 8.5 & 10.8 & 9.7 \\
\hline CBR Index (\%) & 105 & 105 & 115 & 71 \\
\hline CBR Index (soaked 4 day) (\%) & 104 & 98 & 73 & 35 \\
\hline CBR Index (soaked 8 day) (\%) & 81 & 78 & - & - \\
\hline CBR Index (soaked 16 day) (\%) & 113 & 85 & - & - \\
\hline Swelling of CBR samples (\%) & $<0.1$ & $<0.1$ & 0.2 & 0.7 \\
\hline (1) ASTM C 131 - grading A for C\&D 0/70 and grading B for C\&D 0/30 & \\
\hline
\end{tabular}

After the various types of recycled aggregate had been set in place, three tests were carried out to determine the value of the in situ dry density " $\gamma_{\mathrm{ds}}$ " and load plate tests for determination of the modulus of deformation " $\mathrm{M}_{\mathrm{d}}$ " in the pressure interval $0.15-0.25 \mathrm{MPa}$ (Table 4).

Table 4: Mean values of " $\mathrm{M}_{\mathrm{d}}$ " and dry density ratio " $\gamma_{\mathrm{ds}} / \gamma_{\mathrm{dmax}}$ ".

\begin{tabular}{|c|c|c|c|c|}
\hline \multicolumn{1}{|c|}{ Experimental site } & \multicolumn{2}{c|}{ Road 1 } & \multicolumn{2}{c|}{ Road 2 } \\
\hline \multicolumn{1}{|c|}{ Material } & C\&D 0/30 & C\&D 0/70 & C\&D 0/30 & C\&D 0/70 \\
\hline Load plate test $-\mathrm{M}_{\mathrm{d}}(\mathrm{MPa})$ & 85.63 & 36.14 & 94.35 & 34.18 \\
\hline Dry density ratio $\gamma_{\mathrm{ds}} / \gamma_{\mathrm{dmax}}(\%)$ & 98.3 & - & 99.6 & - \\
\hline
\end{tabular}

\section{Tests after 4 years of traffic: year 2001}

After four years of traffic, FWD tests were carried out and the values of in-situ dry density " $\gamma_{\mathrm{ds}}$ " of the two subbases were determined. The FWD test practice and settings as well as mean " $\gamma_{\mathrm{ds}} / \gamma_{\mathrm{dmax}}$ " values are shown in Table 5.

The deflection data acquired were analysed with the ELMOD 5 [2] program using the Method of Equivalent Thickness (MET), which makes it possible to backcalculate the values of the "E" elastic moduli of the pavement layers that most plausibly reproduce the stresses, strains and deflections measured under FWD loading (Ullidtz [3], Ullidtz and Zhang [4]). The values of the "E" moduli 
thereby obtained for the asphalt concrete layer, the subbase and the subgrade, are shown in Figs. 2 and 3.

Table 5: FWD test practice and mean values of " $\gamma_{\mathrm{ds}} / \gamma_{\mathrm{dmax}}$ " - year 2001.

\begin{tabular}{|c|c|c|}
\hline Experimental site & Road 1 & Road 2 \\
\hline Air Temperature $\left({ }^{\circ} \mathrm{C}\right)$ & 26.5 & 30.8 \\
\hline Asphalt Temperature (at asphalt mid-depth) $\left({ }^{\circ} \mathrm{C}\right)$ & 27.8 & 32.0 \\
\hline Loading plate type & \multicolumn{2}{|c|}{ Segmented $-0.3 \mathrm{~m}$ diameter } \\
\hline Geophones distance from centreplate $(\mathrm{m})$ & \multicolumn{2}{|c|}{$0,0.2,0.3,0.45,0.9,1.20,1.50$} \\
\hline Pressure levels $(\mathrm{kPa})$ & \multicolumn{2}{|c|}{$600,800,1000$} \\
\hline Number of drops per station & \multicolumn{2}{|c|}{9 ( 3 each pressure level) } \\
\hline Step $(\mathrm{m})$ & \multicolumn{2}{|c|}{20} \\
\hline Dry density ratio $\gamma_{\mathrm{ds}} / \gamma_{\mathrm{dmax}}(\%)$ & 101.3 & 100.4 \\
\hline
\end{tabular}

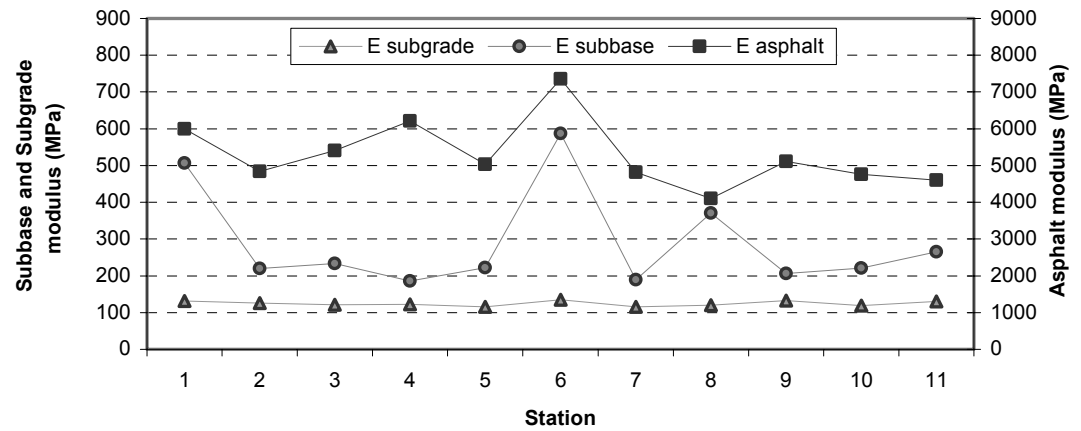

Figure 2: $\quad$ Road 1 - year 2001.

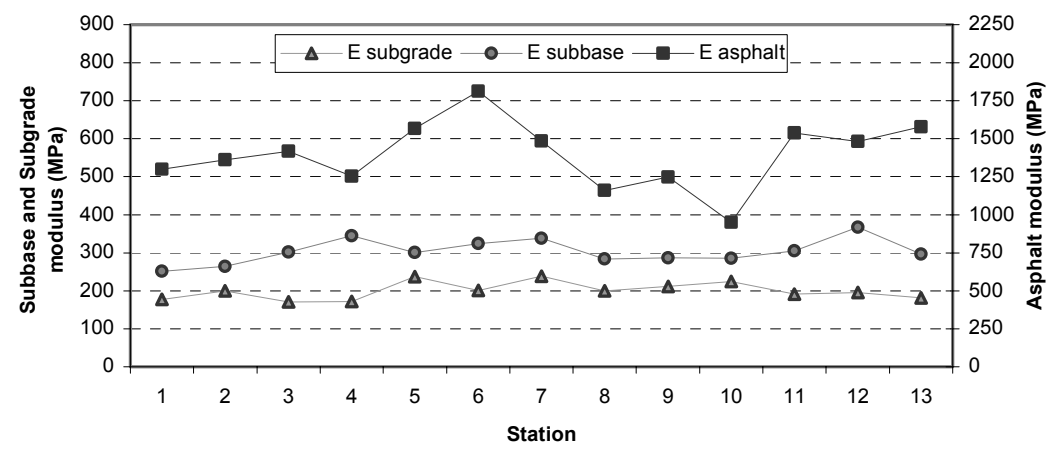

Figure 3: $\quad$ Road 2 - year 2001.

\section{Tests after 8 years of traffic: year 2005}

In October 2005, after 8 years of traffic, both the FWD tests and the determinations of in-situ dry density " $\gamma_{\mathrm{ds}}$ " were repeated. The FWD tests practice and setting as well as mean " $\gamma_{\mathrm{ds}} / \gamma_{\mathrm{dmax}}$ " values are shown in Table 6. 
Table 6: FWD test practice and mean values of " $\gamma_{\mathrm{ds}} / \gamma_{\mathrm{dmax}}$ " - year 2005.

\begin{tabular}{|c|c|c|}
\hline Experimental site & Road 1 & Road 2 \\
\hline Air Temperature $\left({ }^{\circ} \mathrm{C}\right)$ & 21.4 & 22.5 \\
\hline Asphalt Temperature (at asphalt mid-depth) $\left({ }^{\circ} \mathrm{C}\right)$ & 22.0 & 24.1 \\
\hline Loading plate type & \multicolumn{2}{|c|}{ Segmented $-0.3 \mathrm{~m}$ diameter } \\
\hline Geophones distance from centreplate $(\mathrm{m})$ & \multicolumn{2}{|c|}{$0,0.2,0.3,0.45,0.6,0.75,0.9,1.20,1.50$} \\
\hline Pressure levels $(\mathrm{kPa})$ & \multicolumn{2}{|c|}{$600,800,1000$} \\
\hline Number of drops per station & \multicolumn{2}{|c|}{9 (3 each pressure level) } \\
\hline Step $(\mathrm{m})$ & \multicolumn{2}{|c|}{20} \\
\hline Compaction level $\gamma_{\mathrm{ds}} / \gamma_{\mathrm{dmax}}(\%)$ & 102.2 & 100.4 \\
\hline
\end{tabular}

The values of the "E" moduli thereby obtained for the asphalt concrete layer, the subbase and the subgrade, are shown in Figs. 4 and 5.

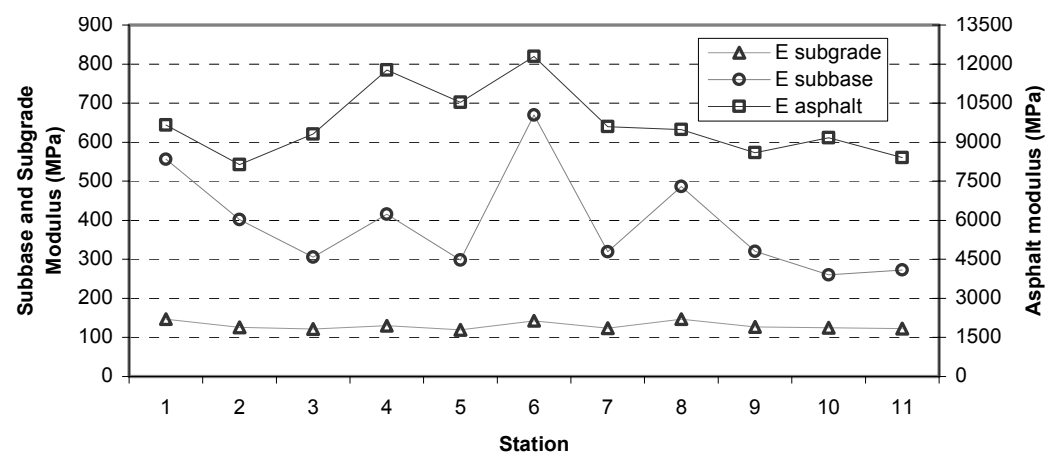

Figure 4: $\quad$ Road 1 - year 2005.

Analysis of the data acquired by means of the Greenwood Laser Profilometer, with $25 \mathrm{~mm}$ sample distance, made it possible to determine the IRI in order to evaluate the longitudinal evenness of the two pavements after 8 years of traffic use. Mean IRI values obtained from three measurements for each of the road section analysed were $1.37 \mathrm{~mm} / \mathrm{m}$ and $3.49 \mathrm{~mm} / \mathrm{m}$ for Road 1 and Road 2 respectively.

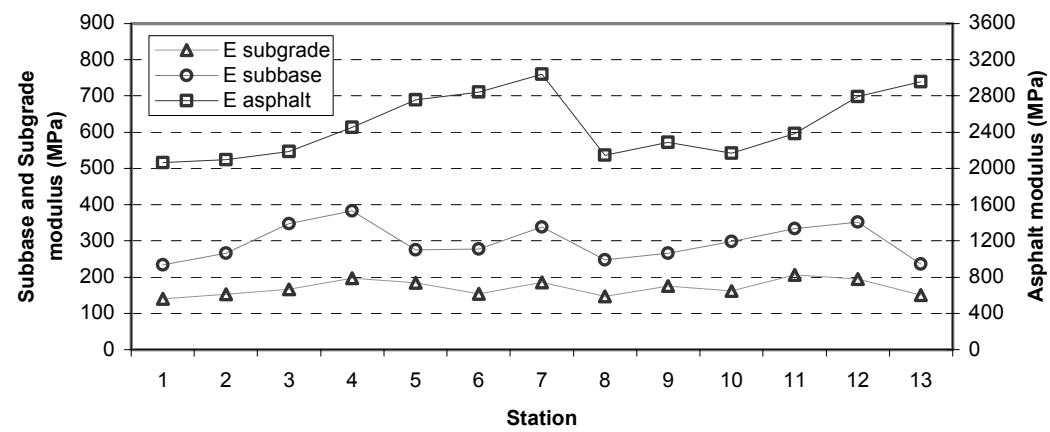

Figure 5: $\quad$ Road 2 - year 2005. 


\section{Analysis of results}

The values of the "E" moduli obtained for the layers constructed with recycled materials, as measured during the 2001 investigations, were found to be higher than had been expected on the basis of the values of the " $\mathrm{M}_{\mathrm{d}}$ " deflection moduli measured by the load plate tests carried out in 1998. If the peak values of stations 1 and 6 of Road 1 are ignored, it can be observed that the mean value of the "E" moduli of the subbase are $235 \mathrm{MPa}$ for Road 1 and $304 \mathrm{MPa}$ for Road 2 (Table 7), roughly 3 times higher than the values obtained with the 1998 static tests. The increase in the moduli found at the end of the first four years of traffic could be attributed to the residual self-cementing properties of the mortar and concrete, contained in percentages of over $17 \%$ in the $0 / 30 \mathrm{C} \& D$ materials utilized for the subbase of Road 1 (Arm [5], Benedetto et al [6]). The mean values of the "E" moduli obtained by elaborations of the deflection data acquired in 2001 and 2005 are shown in Figs. 6 and 7 , while their mean values are summarized in Table 7.

Table 7: $\quad$ Mean values of the moduli backcalculated in 2001 and 2005.

\begin{tabular}{|c|c|c|c|c|c|c|}
\hline \multirow{2}{*}{$\begin{array}{l}\text { Experimental } \\
\text { site }\end{array}$} & \multicolumn{3}{|c|}{ Average moduli $2001(\mathrm{MPa})$} & \multicolumn{3}{|c|}{ Average moduli $2005(\mathrm{MPa})$} \\
\hline & Asphalt & Subbase & Subgrade & Asphalt & Subbase & Subgrade \\
\hline Road 1 & 5296 & 235 & 122 & $5356^{(1)}$ & 379 & 127 \\
\hline Road 2 & 1397 & 304 & 200 & $1117^{(2)}$ & 297 & 170 \\
\hline
\end{tabular}

It should be noted that although the materials utilized for the construction of the two roads were of the same type, they present different physical, mechanical and compositional characteristics. In addition, while Road 1 presents a closed type of wearing course $\left(\mathrm{V}_{\mathrm{v}}=5.5 \%\right)$, which reduces rainwater infiltration into the underlying layers, the Road 2 pavement lacks the wearing course and the surface binder type asphalt layer is highly permeable as it is characterized by an elevated percentage of voids $\left(\mathrm{V}_{\mathrm{v}}>9 \%\right)$.

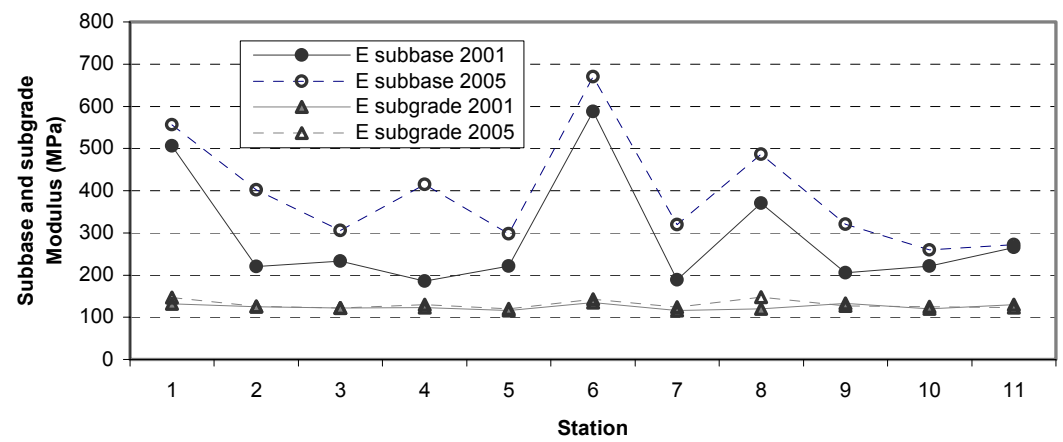

Figure 6: $\quad$ Road 1 - "E” modulus values for 2001 and 2005. 


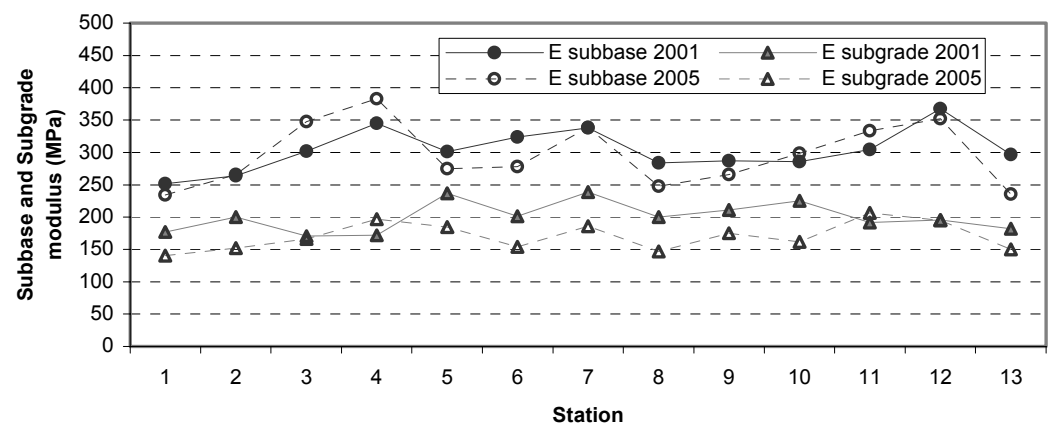

Figure 7: $\quad$ Road 2- "E” modulus values for 2001 and 2005.

For Road 2, the results obtained in 2005 show that the mean value of the "E" modulus of the subbase layer maintains practically the same value as that obtained in 2001, while the mean value of the "E" modulus of the subgrade is roughly $15 \%$ lower compared to that found in the 2001 investigations. This decrease is to be attributed to the high water table in the area where the road is situated (above all in periods of elevated rainfall); such a circumstance, together with rainwater infiltration, leads to a marked presence of moisture content in the subgrade, which, in laboratory tests, exhibited a non-negligible sensitivity to water $(\mathrm{PI}=9)$.

For Road 1, while values of the "E" moduli of the soil subgrade remained almost unaltered from 2001 to 2005 , values of the subbase built of C\&D materials showed a mean increase greater than $34 \%$. This increase cannot be explained by a different extent of the stresses and strains to which the subbase layer is subjected during the FWD tests, arising from a possibly greater stiffness of the overlying asphalt concrete. For as shown in Figure 8, the FWD tests conducted with 3 different levels of stress revealed a more or less linear behavior of the material examined: under the hypothesis that the modulus of the material varies as a function of the bulk stress $(\theta)$ according to the well-known K-Theta model (Hicks and Monismith [7]), for all the test stations the values of the exponential coefficient $\mathrm{K}_{2}$ always ranged between -0.15 and 0.15 , a value that was notably lower than values reported for natural materials in the literature (Domenichini and Di Mascio [8]).

The $34 \%$ increase in the mean value of the "E" modulus recorded between the fourth and eighth year of road use can only partially be explained by the previously mentioned self-cementing properties. It is more likely that this variation can be attributed to further increments in the dry density ratio of the subbase layer resulting from the passage of heavy vehicles (TGM $=320 \mathrm{hv} / \mathrm{d}$,). It should be pointed out that this increase in the value of the "E" modulus is associated with a fairly moderate increase in the dry density ratio.

In order to gain further insight into this phenomenon, specific laboratory investigations were conducted both on the C\&D material and also on an optimal subbase limestone with the same particles size. For this purpose the gyratory compactor was used. This is a viable test device to induce a state of stress in the 
gyratory sample that simulates the passing of a loaded vehicle (McRea [9], George [10]). The values of the dry density ratio that were thereby obtained, evaluated as the ratio between the value achieved with the gyratory compactor $\left(\gamma_{\mathrm{dg}}\right)$ and the maximum AASHTO $\left(\gamma_{\mathrm{dmax}}\right)$ and the corresponding values of the $\mathrm{CBR}$ index recorded at the end of Phase 2 of the compaction procedure, which simulates the effect of vehicular traffic, were compared with values recorded at the end of Phase 1, which simulates compaction at the end of road construction. The results shown in Table 8 demonstrate that for the C\&D material analyzed, given a $0.7 \%$ increase in the dry density ratio at the end of Phase 2 , the increase in the CBR index was roughly $60 \%$. This indicates a higher sensitivity to the degree of compaction than was observed with the natural material. For the latter, given a three times higher increase $(2.3 \%)$ in the dry density ratio, the increase in the CBR index was $16 \%$.

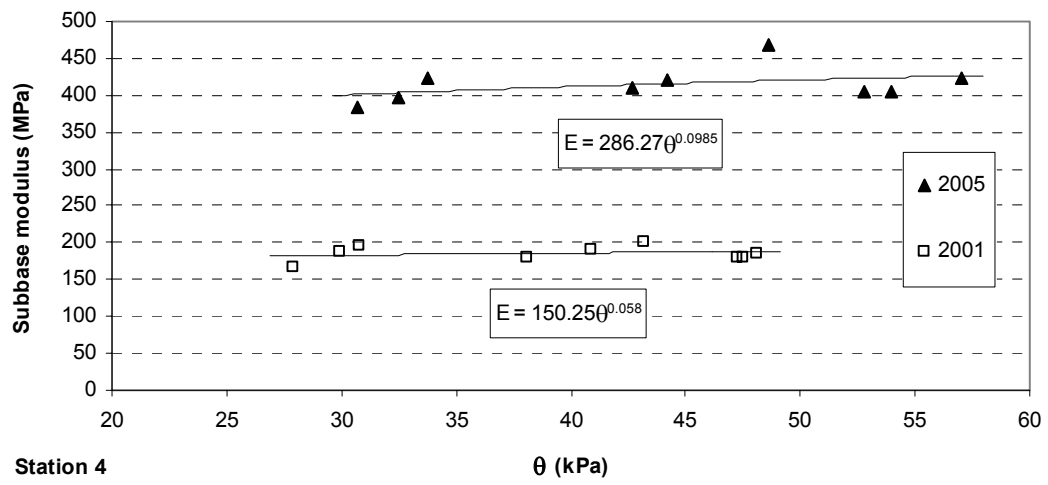

Figure 8: $\quad$ Road 1 - Station 4 - Relationship between bulk stress and subbase modulus.

Table 8: Compaction with gyratory compactor.

\begin{tabular}{|c|c|c|c|c|}
\hline & \multicolumn{2}{|c|}{ Phase 1} & \multicolumn{2}{|c|}{ Phase 2} \\
\hline Angle of gyration $\left(^{\circ}\right)$ & \multicolumn{2}{|c|}{$1.25 \pm 0.02$} & \multicolumn{2}{|c|}{$1.25 \pm 0.02$} \\
\hline Speed of gyration (rev/min) & \multicolumn{2}{|c|}{30} & \multicolumn{2}{|c|}{30} \\
\hline $\begin{array}{l}\text { Number of gyrations } \\
\text { and ram pressure }\end{array}$ & \multicolumn{2}{|c|}{$\begin{array}{l}90 \text { gyrations }-\mathrm{P}=600 \mathrm{kPa} \\
90 \text { gyrations }-\mathrm{P}=300 \mathrm{kPa}\end{array}$} & \multicolumn{2}{|c|}{$\begin{array}{r}90 \text { gyrations }-\mathrm{P}=600 \mathrm{kPa} \\
90 \text { gyrations }-\mathrm{P}=300 \mathrm{kPa} \\
400 \text { gyrations }-\mathrm{P}=200 \mathrm{kPa}\end{array}$} \\
\hline Aggregates for subbase layers & C\&D 0/30 & Virgin & $\mathrm{C} \& \mathrm{D} 0 / 30$ & Virgin \\
\hline High specimen $(\mathrm{mm})$ & 117.6 & 124.7 & 116.7 & 121.8 \\
\hline Dry density ratio $\gamma_{\mathrm{dg}} / \gamma_{\mathrm{dmax}}(\%)$ & 101.85 & 100.26 & 102.53 & 102.51 \\
\hline CBR Index (\%) (Mean of 3 values) & 128 & 172 & 188 & 198 \\
\hline
\end{tabular}

\section{Conclusions}

Analysis of the data acquired during the 2001 tests shows that for both of the roads examined, mean values of the " $E$ " moduli of the respective subbases were roughly 3 times the " $\mathrm{M}_{\mathrm{d}}$ " values obtained in 1998. On Road 1 the values of the 
moduli recorded in 2005 were, on average, 34\% higher compared to those recorded in 2001. On Road 2 the values of the subbase obtained in 2005 virtually replicated the value recorded in 2001 (roughly $300 \mathrm{MPa}$ ) while the value of the modulus of the corresponding subgrade decreased by $15 \%$ (from $200 \mathrm{MPa}$ to $170 \mathrm{MPa})$.

The increase in the moduli between the fourth and eighth year of traffic can be attributed to the residual self-cementing properties of the material, combined with the effect of traffic, which may have induced further compaction of the layer but without compromising the evenness of the pavement surface. This hypothesis was confirmed through purpose-designed laboratory tests with the gyratory compactor, which demonstrated that in this type of materials small variations in the dry density ratio can lead to significant increases in the CBR index (roughly $60 \%$ ), unlike to findings for the optimal natural material with the same particles size used as term of comparison.

The reduction in the moduli of the subgrade of Road 2 can likely be attributed to the silty-clayey fractions contained in the C\&D 0/70 and to the greater moisture content present in the subgrade itself.

However, for both of the roads analyzed, the layers constructed with materials deriving from recycled construction and demolition waste were shown to maintain over time a performance that was by no means inferior to that characterizing traditional materials. Furthermore, results both of in-situ and laboratory tests revealed that the load-bearing capacity of the material had elevated sensitivity to the dry density ratio.

We therefore conclude that in order to achieve a good performance with these materials it is advisable to carry out preliminary laboratory tests designed to establish a reliable and significant correlation between compaction and loadbearing capacity, so that appropriate knowledge can be acquired for correct utilization of the materials.

\section{References}

[1] Marradi, A., Indagini sperimentali sui materiali inerti di riciclaggio, Riciclare per l'ambiente, ed. Grafica Pisana, Pisa, pp.72-89,1999.

[2] Elmod $5 \mathrm{FWD}$ data analysis software, Dynatest International $\mathrm{A} / \mathrm{S}$, Denmark, 2005.

[3] Ullidtz, P., Modelling Flexible Pavement Response and Performance, Denmark, 1998.

[4] Ullidtz, P. \& Zhang, W., Back-calculation of pavement layer moduli and forward-calculation of stresses and strains. ISAP $9^{\text {th }}$ conference, Copenhagen 2002.

[5] Arm, M., Self-cementing properties of crushed demolished concrete in unbound layers: results from triaxial tests and field test, Waste Management No. 21, pp. 235-239, 2001.

[6] Benedetto, A.,Benedetto, C. \& De Blasiis, M. R., Le potenzialità del riciclato. Recycling, pp.81-91, July 2005. 
[7] Hicks, R.G. and Monismith, C.L., Factors Influencing the Resilient Properties of Granular Materials. Transportation Research Record No. 345, TRB, National Research Council, Washington DC, 1971, pp. 15-31.

[8] Domenichini, L \& Di Mascio, P., I materiali non legati impiegati nelle sovrastrutture stradali, pp. 32-48, 1990.

[9] McRea, J. L., Gyratory compaction method for determining density requirements for subgrade and base of flexible pavements. Miscellaneous Paper No. 4-494, U.S. Army Engineering Waterways Experiment Station, Corps of Engineering, Vicksburg, Miss, 1962.

[10] George, K.P., Resilient testing of soils using gyratory testing machine. Transportation Research Record No. 1369, TRB, National Research Council, Washington DC, pp.63-72, 1992. 